\title{
Association between adverse childhood experiences, bullying, self-esteem, resilience, social support, caries and oral hygiene in children and adolescents in sub- urban Nigeria
}

\author{
Morenike Oluwatoyin Folayan ${ }^{1,2^{*}}$ (D), Olakunle Oginni ${ }^{1,2}$, Olaniyi Arowolo ${ }^{1}$ and Maha El Tantawi ${ }^{3}$
}

\begin{abstract}
Background: Adverse childhood experiences (ACE) and bullying have negative effects on oral health. Promotive assets (resilience, self-esteem) and resources (perceived social support) can ameliorate their negative impact. The aim of this study was to determine the association between oral diseases (caries, caries complications and poor oral hygiene), ACE and bully victimization and the effect of access to promotive assets and resources on oral diseases.

Methods: This was a secondary analysis of data collected through a cross-sectional school survey of children 6-16years-old in Ile-Ife, Nigeria from October to December 2019. The outcome variables were caries, measured with the dmft/DMFT index; caries complications measured with the pufa/PUFA index; and poor oral hygiene measured with the oral hygiene index-simplified. The explanatory variables were ACE, bully victimization, resilience, self-esteem, and social support. Confounders were age, sex, and socioeconomic status. Association between the explanatory and outcome variables was determined with logistic regression.
\end{abstract}

Results: Of the 1001 pupils with complete data, 81 (8.1\%) had poor oral hygiene, 59 (5.9\%) had caries and 6 (10.2\%) of those with caries had complications. Also, 679 (67.8\%) pupils had one or more ACE and 619 (62.1\%) pupils had been bullied one or more times. The median (interquartile range [IQR]) for ACE was 1(3), for bully victimization was 1(5), and for self-esteem and social support scores were 22(5) and 64(34) respectively. The mean (standard deviation) score for resilience was 31(9). The two factors that were significantly associated with the presence of caries were self-esteem (AOR: 0.91; 95\% Cl: 0.85-0.98; $p=0.02$ ) and social support (AOR: $0.98 ; 95 \%$ Cl: $0.97-1,00 ; p=$ 0.02). No psychosocial factor was significantly associated with caries complications. Self-esteem was associated with poor oral hygiene (AOR: 1.09; 95\% Cl: 1.09-1.17; $p=0.03$ ).

(Continued on next page)

\footnotetext{
*Correspondence: toyinukpong@yahoo.co.uk

'Obafemi Awolowo University Teaching Hospitals Complex, Ile-Ife, Nigeria

${ }^{2}$ Department of Child Dental Health, Obafemi Awolowo University, lle-lfe, Nigeria

Full list of author information is available at the end of the article
}

(c) The Author(s). 2020 Open Access This article is licensed under a Creative Commons Attribution 4.0 International License, which permits use, sharing, adaptation, distribution and reproduction in any medium or format, as long as you give appropriate credit to the original author(s) and the source, provide a link to the Creative Commons licence, and indicate if changes were made. The images or other third party material in this article are included in the article's Creative Commons licence, unless indicated otherwise in a credit line to the material. If material is not included in the article's Creative Commons licence and your intended use is not permitted by statutory regulation or exceeds the permitted use, you will need to obtain permission directly from the copyright holder. To view a copy of this licence, visit http://creativecommons.org/licenses/by/4.0/. The Creative Commons Public Domain Dedication waiver (http://creativecommons.org/publicdomain/zero/1.0/) applies to the data made available in this article, unless otherwise stated in a credit line to the data. 
(Continued from previous page)

Conclusion: There was a complex relationship between ACE, bully victimization, access to promotive assets and resources by children and adolescents, and oral health. ACE and bully victimization were not associated with oral health problems. Though self-esteem was associated with caries and poor oral hygiene, the relationships were inverse. Promotive assets and resources were not associated with caries complications though resources were associated with lower prevalence of caries.

Keywords: Adverse childhood events, Nigeria, Children, Adolescents, Psychosocial factors, Culture

\section{Background}

Adverse childhood experiences (ACE) are negative life events that are detrimental to brain development, and are root causes of diseases and mortality [1]. ACE occur before the age of 18 years [1], and include physical, sexual and emotional abuse and neglect, as well as bullying victimization and parental separation. They directly increase the likelihood of a child having poor oral health, including dental caries [2-4], and are also associated with adult health risks, such as cardiovascular diseases [5], diabetes mellitus [6] and smoking [7] which in turn, are associated with poor oral health in adulthood [8-10]. ACE further have negative impacts on the neuroendocrine-immune system and host defense mechanism [11] thereby causing high psychological stress [12] that increase the risk for poor oral hygiene and, thereby, caries [13].

Vasiliou et al. [14] developed a conceptual framework from the works of Shankardass [15] and Pearlin et al. [16], to explain the possible link between psychological stress and poor oral health. They suggested that ACE may translate into chronic stress in the absence of promotive assets (resilience, self-esteem) and resources (perceived social support). Chronic stress results in allostatic load, a cumulative physiological impact of chronic stress, that impacts negatively on oral health directly (by increasing inflammatory response which causes periodontal disease $[17,18]$ ) or indirectly (by causing the adoption of unhealthy oral habits such as poor oral maintenance that can result in poor oral hygiene and caries).

Another adverse factor that may have a negative impact on oral health is bully victimization. Bully victimization is defined as the experience of distress or feeling of being controlled by others through aggression and/or power [19]. Good oral health enables children to have a healthy smile, which may be associated with less bully victimization [20]. Multiple studies indicate that poor dental aesthetics [21-23] and untreated caries [24] increase the risk for bully victimization. Poor oral hygiene causes halitosis, and halitosis is a risk factor for bully victimization [25]. In addition, poor dental aesthetics [26] and caries [27-29] have negative emotional and social effects on oral health-related quality of life because of their negative impact on self-esteem and selfconcept. The history, frequency and consequences of bully victimization also affects oral health related quality of life [30, 31].

Protective factors can mitigate the relationship between ACE and bully victimization and children's oral health $[4,32]$ by enhancing one's ability to use available resources to manage life's difficulties and maintain one's health [33, 34]. One of these protective factors is high self-esteem [35]. Improving self-esteem was found to be effective for the management of children with cleft lip and palate [36]. Other individual factors that protect against the negative impact of adverse life events are one's resilience [37] and access to support [38]. Resilience - an individual's trait-like ability to demonstrate stable level of functioning despite adversity - acts as a buffer that facilitates positive outcomes despite exposure to adverse life events [39]. Social support also acts as a buffer against the stress that results from adverse life events by enhancing cognitive and emotional processing of the stressful event in a manner that is psychologically adaptive [40].

There is a scarcity of studies determining the relationship between children's adverse experiences, bullying victimization, protective psychosocial factors and oral health for African populations, despite the identified relationship between these factors [41] and the importance of culture and context in moderating these relationships [42-44]. Individuals pull on external and internal resources to help them manage, cope with, or resolve tensions in health-promoting ways that reduce stress [33, 34]. Culture influences how individuals deal with tensions and how they identify resources to manage stresses [34]. Africans may be more collectivist-oriented than populations in the Global North who may value individualism and liberalism to a greater extent $[45,46]$.

This study was conducted in a suburban community in Nigeria, West Africa. This is a collectivist community where the rights and interests of individuals are subordinate to the good of the community. It is a community that holds traditional patriarchal beliefs and strong religious and extended family ties [47]. The study 
determined the relationship between ACE and exposure to bully victimization and oral health status accounting for factors that help overcome the negative effects of these risk factors. Specifically, the study explored the association between oral diseases (caries, caries complications and poor oral hygiene), ACE, bully victimization and promotive assets (resilience, self-esteem) and resources (perceived social support) [48] in schoolchildren in Ile-Ife, Nigeria.

\section{Methods}

\section{Ethical consideration}

Approval for the study was obtained from the Research and Ethics Committee of the Obafemi Awolowo University Teaching Hospitals Complex, Ile-Ife, Nigeria (ERC/ 2018/08/06). Permission was obtained from the Local Government Education Authority, Osun State, and the authorities of schools involved in this study.

Informed consent for study participation was obtained from the parents of all eligible pupils enrolled in the study and assent was obtained from children 12-16 years old. The consent and assent forms were sent to parents ahead of the school-visit date. On the day of the visit, only children who had the filled and signed informed consent forms and, where appropriate, the assent forms were included in the study. When parents/guardians had not signed an informed consent form but the child was keen to participate in the study, the child's parent(s)/ guardian(s) were called by telephone to seek verbal consent, and a filled written consent was obtained retroactively. The phone conversation was recorded. If the parent/guardian showed no interest in child/ward participation, the child was excluded from the study. Data were collected anonymously. Students did not receive reimbursement for study participation.

\section{Study design and study population}

This is a secondary analysis of data collected to determine the association between caries and nutritional status. The primary study was a cross-sectional study that recruited children aged 6 to 16 years attending private and public primary and secondary schools in Ife Central Local Government Area, Ile-Ife, Osun State, Nigeria from October to December 2019. Children and adolescents with special health-care needs, those who were ill, and those who had fasted within a period of 3 months before data collection, were excluded from the study. The age 6-years was chosen as the lower limit because they would have developed the cognitive ability to respond to the questionnaire $[49,50]$.

\section{Sample size}

The sample size for the primary study was determined according to the formula of Metcalfe [51] and using a caries prevalence of $13.9 \%$ as had been determined in a prior study in the population [52]. To recruit 168 children with dental caries, underweight, normal weight, overweight and obesity, 1209 children were required to give a power of $80 \%$. The sample for the primary study was 1502 .

\section{Sampling procedure}

A multi-stage cluster sampling technique was used to recruit participants for the primary study. Children 6-10 years of age were recruited from primary schools, while those who were 11-16 years old were recruited from secondary schools.

First, schools were stratified into primary and secondary schools. The ratio of primary to secondary schools in the study population was $2: 1$ and the ratio of public to private school was 1:4. Next, 20 primary schools (3 public, and 17 private) and 10 secondary schools ( 2 public and 8 private) were randomly selected. At the schools, the class registration list was used to identify classes with the highest number of children. Children from the selected classes were asked to pick ballot papers with 'yes' or 'no' options. Those who picked 'yes' were recruited for the study.

\section{Data collection instruments}

An interviewer-administered questionnaire collected data on participant's sex, age at last birthday (6-11-yearold and 12-16-year-old), and child's socioeconomic status [53]. Other sections of the questionnaire are as follows:

\section{Adverse childhood experiences}

were measured according to the 10-item Adverse Childhood Experiences Questionnaire, which provides a measure of cumulative life stress experienced during childhood [54]. These include experiences of parental verbal or physical assault, parental divorce, witnessing of maternal or grandmother's physical abuse, experiences of emotional deprivation, sexual assault, and/or having a family member who is an alcoholic, mentally ill or an ex-convict. The instrument has been validated for use in Nigeria [55]. The response to each of the 10 questions is either 'yes' or 'no,' with possible score ranges from 0 to 10. The higher the score the more life adversities the child has faced.

\section{Childhood bully victimization}

was assessed with the victim subscale of the Illinois Bully Scale [56] and has been validated for use in Nigeria with a Cronbach's alpha score of 0.78 [57]. The subscale consists of four questions that measure both physical and verbal victimization that individuals experience from or by peers. The responses to each question ranged from 
never (scored 0) to 1-2 times (1), 3-4 times (2), 5-6 times (3), and 7 or more times (4). The responses were summed to derived a total score which ranged from 0 to 16.

\section{Self-esteem}

was assessed with the 10-item Rosenberg's self-esteem scale. Items are scored on a Likert-like scale with options ranging from "Strongly Disagree" (1 point), "Disagree" (2 points), "Agree" (3 points) to "Strongly Agree" (4 points). The scale has good psychometric properties [58] and has been validated for use among adolescents in Nigeria with a Cronbach's alpha score of 0.88 [59]. Items 2, 5, 6, 8, 9 were reverse-scored and sum score was derived which ranged from 10 to 40 with higher scores indicating lower self-esteem. The continuous scores were used in analyses.

\section{Resilience}

was assessed with the 10-item Connor-Davidson resilience scale, which was validated for use in Nigeria with a Cronbach's alpha score of 0.81 [60]. Each item is rated on a 5-point scale from 0 ('not true at all') to 4 ('true nearly all the time'). The possible total score ranges from 0 to 40 with higher scores indicating higher resilience.

\section{Social support}

was assessed with the 12-item multidimensional perceived social support scale $[61,62]$. The scale has three subscales which inquired about an individual's perception of the adequacy of support from family, friends, and significant-others' family. Each subscale comprised four questions. Each item was rated on a 7-point Likert-type response format ranging from 1 "very strongly agree" to 7- "very strongly disagree." The possible total score ranged from 12 to 84 with higher total scores corresponding to higher levels of perceived social support, while lower scores indicated perceived unavailability or lack of social support [63]. The scale had been validated for use in Nigeria with a Cronbach's alpha score of 0.78 [64].

\section{Oral hygiene status}

Intra-oral examination assessed oral hygiene status using the Simplified Oral Hygiene Index [65]. The oral hygiene score ranges from 0 to 6 categorized into $0.0-1.2$ indicating good oral hygiene; $1.3-3.0$ as fair oral hygiene; and 3.1-6.0 as poor oral hygiene. The oral hygiene status was dichotomized into good (0.0-3.0) and poor (3.16.0) status for the logistic regression analysis.

\section{Caries status and complications}

Intra-oral examination was also conducted according to the World Health Organization criteria of caries examination to determine the presence of decayed, missing teeth, and filled teeth due to caries using $\mathrm{dmft}$ /DMFT indices [66]. Caries status was determined after the oral hygiene status was assessed. Teeth were cleaned with gauze and examined under natural light with dental mirrors without probes. Children were examined seated on a chair. The dmft /DMFT indices were used to categorize the children's caries status: $\mathrm{dmft} / \mathrm{DMFT}=0$ was categorized into caries absent while dmft /DMFT greater or equal to 1 was categorized as caries present. The proportion of children with and without caries was computed.

The dmft /DMFT indices were also used to define the severity of caries for children with caries. Dmft /DMFT greater or equal to 3 was categorized as severe caries while dmft /DMFT scores of 0.1-2.99 was categorized as low caries severity,

Complications associated with carious lesions were assessed with the pufa/PUFA index [67], which was computed for children who had caries. When the pufa/ PUFA score was 0 , the child was categorized as not having caries complications. Children with a pufa/PUFA score greater than 0 were categorized as having caries complications.

\section{Study procedure}

Participants were examined seated on a chair in a private area, which was well illuminated with natural light, in the school compound in the presence of a school chaperone. Oral hygiene status was assessed after the questionnaire was filled. The examination was conducted by an examiner and recorded by the assistant. The examiner was calibrated on use of the dmft/DMFT and PUFA/pufa index. The examiner was first calibrated by a consultant and the inter-examiner reliability kappa score was 0.85 . Next, an intra-examiner reliability (conducted 1 week after the first examination) was conducted with a kappa score of 0.90 .

\section{Data analysis}

The normal distribution of the explanatory variables (ACE, bully victimization, self-esteem, resilience, social support) was determined. The mean (SD) and median (Interquartile range - IOR) of the scores for the explanatory variables were computed. The association between the categorized outcome variables (caries, complications of caries, and poor oral hygiene) and age, sex, socioeconomic status was assessed using chi square test or Mann Whitney $U$ test. The associations with the explanatory variables (ACE, bully victimization, self-esteem, resilience and social support) were determined using the Mann Whitney U test and Kruskal-Wallis test for the variables that were skewed and the $t$ test for those that were normally distributed. Univariate and multivariable 
logistic regression was conducted to determine the crude and adjusted odds ratios. The models to determine the risk indicators for poor oral hygiene, caries, and complications of caries were adjusted for age, sex and socioeconomic status, which are factors associated with caries, oral hygiene status of children and ACE [68-70]. Statistical significance was conducted with Stata/SE 14.0 for Windows (2015) and measured as $p \leq 0.05$.

\section{Results}

The data of 1001 (66.6\%) of the 1502 collected data with complete information was extracted. Of these, 549 (54.8\%) were girls, 962 (96.1\%) aged 11-16-year-olds, and $586(58.5 \%)$ children were from middle socioeconomic status. Eighty-one (8.1\%) children had poor oral hygiene.

Fifty-nine (3.9\%) children had caries. The dmft ranged from 0 to 4 , with nearly all (99.4\%) having $0 \mathrm{dmft}$. The DMFT ranged from 0 to 6 , with most having 0 (94.5\%) DMFT. Of the children with caries, 6 (10.2\%) had complications. The pufa score was 0 while the PUFA score ranged from 1 to 3 . No child with high socioeconomic status had caries complications.

ACE score ranged from 0 to 10 with a median (IQR) score of 1 (3). Also, 679 (67.8\%) had one or more ACE. The childhood bully victimization score ranged from 0 to 16 with a median (IQR) score of 1 (5). Also, 619 $(62.1 \%)$ had been bullied one or more times. The selfesteem score ranged from 3 to 31 with a median (IQR) score of 22 (5). The perceived social support score ranged from 3 to 81 with a with a median (IQR) score of 64 (34). The resilience score ranged from 8 to 50 with a mean (SD) score of 31 (9).

Table 1 highlights the association between age, sex, socioeconomic status and the prevalence and severity of caries, caries complications and oral hygiene status. There was no significant association between sex $(p=$ $0.86)$, socioeconomic status $(p=0.36)$ and age $(p=0.72)$ and the prevalence of caries; nor was there a significant association between sex $(p=0.51)$, socioeconomic status $(p=0.19)$ and age $(p=1.00)$ and caries severity. In addition, there was no significant association between sex $(p=0.39)$, socioeconomic status $(p=0.15)$ and age $(\mathrm{p}=1.00)$ and caries complications; nor was there a significant association between age $(p=0.07)$, and sex $(p=$ 0.11 ) and oral hygiene status. However, there was an association between socioeconomic status and oral hygiene; a greater percentage of children with good oral hygiene than those with fair or poor oral hygiene were from low socioeconomic status $(P=0.02)$.

Table 2 shows the associations between the explanatory and outcome variables for the study in bivariate analysis. There were no significant differences in ACE score between children with and without caries $(p=$ $0.74)$; with low and high caries severity $(p=0.43)$, with and without caries complications $(p=0.60)$; and with good, fair and poor oral hygiene $(p=0.45)$.

There were no significant associations between childhood bully victimization score and the proportion of

Table 1 Association between sex, socioeconomic status and age and prevalence and severity of caries, caries complication and oral hygiene status in children 6-16 years old resident in Ile-lfe, Nigeria

\begin{tabular}{|c|c|c|c|c|c|c|c|c|c|c|}
\hline \multirow[t]{3}{*}{ Variables } & \multicolumn{2}{|l|}{$\begin{array}{l}\text { Caries } \\
N=1001 \\
\end{array}$} & \multicolumn{2}{|c|}{$\begin{array}{l}\text { dmft/DMFT } \\
N=59\end{array}$} & \multicolumn{2}{|c|}{$\begin{array}{l}\text { Caries complications } \\
N=59\end{array}$} & \multicolumn{3}{|l|}{$\begin{array}{l}\text { Oral hygiene } \\
N=1001\end{array}$} & \multirow[t]{2}{*}{$\begin{array}{l}\text { Total } \\
\boldsymbol{N}=1001\end{array}$} \\
\hline & $\begin{array}{l}\text { Absent } \\
\boldsymbol{n}=942\end{array}$ & $\begin{array}{l}\text { Present } \\
\boldsymbol{n}=59\end{array}$ & $\begin{array}{l}1-2 \\
n=48\end{array}$ & $\geq^{2}=11$ & $\begin{array}{l}\text { Absent } \\
\boldsymbol{n}=53\end{array}$ & $\begin{array}{l}\text { Present } \\
\boldsymbol{n}=6\end{array}$ & $\begin{array}{l}\text { Good } \\
\boldsymbol{n}=37\end{array}$ & $\begin{array}{l}\text { Fair } \\
\boldsymbol{n}=883\end{array}$ & $\begin{array}{l}\text { Poor } \\
\boldsymbol{n}=81\end{array}$ & \\
\hline & $\begin{array}{l}\text { Number } \\
(\%)\end{array}$ & $\begin{array}{l}\text { Number } \\
(\%)\end{array}$ & $\begin{array}{l}\text { Number } \\
(\%)\end{array}$ & $\begin{array}{l}\text { Number } \\
(\%)\end{array}$ & $\begin{array}{l}\text { Number } \\
(\%)\end{array}$ & $\begin{array}{l}\text { Number } \\
(\%)\end{array}$ & Number (\%) & $\begin{array}{l}\text { Number } \\
(\%)\end{array}$ & $\begin{array}{l}\text { Number } \\
(\%)\end{array}$ & $\begin{array}{l}\text { Number } \\
(\%)\end{array}$ \\
\hline \multicolumn{11}{|l|}{ Sex } \\
\hline Male & $516(54.8)$ & $33(55.9)$ & $28(58.3)$ & $5(45.5)$ & $31(58.5)$ & $2(33.4)$ & $23(61.2)$ & $490(55.5)$ & $36(44.4)$ & $549(54.8)$ \\
\hline Female & $426(45.2)$ & $26(44.1)$ & $20(41.7)$ & $6(54.5)$ & $22(41.5)$ & $4(66.6)$ & $14(38.8)$ & $392(44.5)$ & $45(55.6)$ & $452(145.2)$ \\
\hline$p$ value & 0.86 & & 0.51 & & 0.39 & & 0.11 & & & \\
\hline \multicolumn{11}{|c|}{ Socioeconomic status } \\
\hline Low & $272(28.9)$ & $12(20.3)$ & $8(16.7)$ & $4(36.4)$ & $9(17.0)$ & $3(50.0)$ & 19 (51.4) & $242(27.5)$ & $22(27.2)$ & $284(28.4)$ \\
\hline Middle & $547(58.1)$ & $39(66.1)$ & $32(66.7)$ & $7(63.6)$ & $36(67.9)$ & $3(50.0)$ & $16(43.2)$ & $526(59.6)$ & $44(54.3)$ & $586(58.5)$ \\
\hline High & $123(13.0)$ & $8(13.6)$ & $8(16.6)$ & $0(0.0)$ & $8(15.10)$ & $0(0.0)$ & $2(5.4)$ & $114(12.9)$ & $15(18.5)$ & $131(13.1)$ \\
\hline$p$ value & 0.36 & & 0.19 & & 0.15 & & $0.02^{*}$ & & & \\
\hline \multicolumn{11}{|l|}{ Age } \\
\hline 6-10-year-olds & $38(4.0)$ & $1(1.7)$ & $1(2.1)$ & $0(0.0)$ & $1(100.0)$ & $0(0.0)$ & $4(10.8)$ & $31(3.5)$ & $4(4.9)$ & $39(3.9)$ \\
\hline 11-16-year-olds & $904(96.0)$ & $58(58.3)$ & 47 (97.9) & $11(100.0)$ & 52 (89.7) & $6(100.0)$ & $33(89.2)$ & $851(96.5)$ & 77 (95.1) & $962(96.1)$ \\
\hline$p$ value & 0.72 & & 1.00 & & 1.00 & & 0.07 & & & \\
\hline
\end{tabular}


Table 2 Adverse childhood experience, bully victimization, self-esteem, resilience and social support scores per prevalence and caries severity, caries complication and oral hygiene status in children 6-16-years-old resident in Ile-lfe, Nigeria

\begin{tabular}{|c|c|c|c|c|c|c|c|c|c|c|c|c|c|}
\hline \multirow[t]{3}{*}{ Variables } & \multicolumn{3}{|l|}{$\begin{array}{l}\text { Caries } \\
N=1001\end{array}$} & \multicolumn{3}{|c|}{$\begin{array}{l}\text { dmft/DMFT } \\
N=59\end{array}$} & \multicolumn{3}{|c|}{$\begin{array}{l}\text { Caries complication } \\
N=59\end{array}$} & \multicolumn{4}{|c|}{$\begin{array}{l}\text { Oral hygiene } \\
N=1001\end{array}$} \\
\hline & $\begin{array}{l}\text { Absent } \\
n=942\end{array}$ & $\begin{array}{l}\text { Present } \\
n=59\end{array}$ & $\overline{p \text {-value }}$ & $\begin{array}{l}1-2 \\
n=48\end{array}$ & $\begin{array}{l}\geq 3 \\
n=11\end{array}$ & $p$-value & $\begin{array}{l}\text { Absent } \\
n=53\end{array}$ & $\begin{array}{l}\text { Present } \\
n=6\end{array}$ & $\overline{p \text {-value }}$ & $\begin{array}{l}\text { Good } \\
n=37\end{array}$ & $\begin{array}{l}\text { Fair } \\
n=883\end{array}$ & $\begin{array}{l}\text { Poor } \\
n=81\end{array}$ & $p$-value \\
\hline & $\begin{array}{l}\text { Median } \\
\text { (IQR) }\end{array}$ & $\begin{array}{l}\text { Median } \\
\text { (IQR) }\end{array}$ & & $\begin{array}{l}\text { Median } \\
\text { (IQR) }\end{array}$ & $\begin{array}{l}\text { Median } \\
\text { (IQR) }\end{array}$ & & $\begin{array}{l}\text { Median } \\
\text { (IQR) }\end{array}$ & $\begin{array}{l}\text { Median } \\
\text { (IQR) }\end{array}$ & & $\begin{array}{l}\text { Median } \\
\text { (IQR) }\end{array}$ & $\begin{array}{l}\text { Median } \\
\text { (IQR) }\end{array}$ & $\begin{array}{l}\text { Median } \\
\text { (IQR) }\end{array}$ & \\
\hline$\overline{\mathrm{ACE}}$ & $1(3)$ & $1(1)$ & 0.74 & $1(2)$ & $1(1)$ & 0.43 & $1(1)$ & $1(0)$ & 0.60 & $1(3)$ & $1(2)$ & $2(3)$ & 0.45 \\
\hline $\begin{array}{l}\text { Bully } \\
\text { victimization }\end{array}$ & $1(5)$ & $2(5)$ & 0.37 & $2(4.5)$ & $4(7)$ & 0.63 & $2(5)$ & $0.5(2)$ & 0.11 & $1(4)$ & $2(6)$ & $1(4)$ & 0.17 \\
\hline Self esteem & $22(5)$ & $21(5)$ & 0.03 & $21(5)$ & $20(5)$ & 0.95 & $21(5)$ & $21(5)$ & 0.97 & $22(5)$ & $22(5)$ & $22(4)$ & 0.13 \\
\hline Social support & $64(34)$ & $59(30)$ & 0.08 & $58.5(29)$ & $60(38)$ & 0.63 & $59(29)$ & $58.5(25)$ & 0.65 & $63(24)$ & $64(34)$ & $59.5(32)$ & 0.50 \\
\hline Resilience $^{\mathrm{a}}$ & $31.7(8.7)$ & $31(9.2)$ & 0.55 & $31.5(8.1)$ & $32.6(11.4)$ & 0.70 & $26(10)$ & $32.4(8.4)$ & 0.09 & $29.3(9.6)$ & $31.2(9)$ & $29.7(9.7)$ & 0.18 \\
\hline
\end{tabular}

${ }^{a}$ Mean (SD) was computed, and the $p$ value was computed using t-test

children with and without caries $(p=0.37)$, with low and high caries severity $(p=0.63)$, with and without caries complications $(p=0.11)$, and with good, fair and poor oral hygiene $(p=0.17)$.

There were also no significant associations between self-esteem score and the proportion of children with low and high caries severity $(p=0.95)$, with and without caries complications $(p=0.97)$, and with good, fair and poor oral hygiene $(p=0.13)$. There was however, a significant difference in self-esteem score of children with and without caries $(p=0.03)$ : the median (IQR) selfesteem score of children with caries was lower than the median (IQR) of children without caries (21(5) vs 22 (5). See Table 2.
There were no significant associations between the social support score and the proportion of children with and without caries $(p=0.08)$, children with low and high caries severity $(p=0.63)$, with and without caries complications $(p=0.65)$; and with good, fair and poor oral hygiene $(p=0.50)$. See Table 2 .

There were no significant associations between resilience score and the proportion of children with and without caries $(p=0.55)$, children with low and high caries severity $(p=0.70)$, with and without caries complications $(p=0.09)$; and with good, fair and poor oral hygiene $(p=0.18)$. See Table 2 .

Table 3 shows the factors associated with poor oral hygiene after logistic regression analysis. While in the

Table 3 Logistic regression analysis to determine psychosocial factors associated with poor oral hygiene in children 6-16-years-old resident in Ile-Ife, Nigeria $(N=1001)$

\begin{tabular}{|c|c|c|c|c|}
\hline Variables & $\begin{array}{l}\text { Odds ratio } \\
\text { (95\% Confidence interval) }\end{array}$ & $\boldsymbol{P}$ value & $\begin{array}{l}\text { Adjusted odds ratio } \\
\text { (95\% Confidence interval) }\end{array}$ & $\boldsymbol{P}$ value \\
\hline \multicolumn{5}{|l|}{ Sex } \\
\hline Female & 1.00 & - & 1.00 & - \\
\hline Male & $1.58(1-2.49)$ & 0.05 & $1.78(1.1-2.88)$ & 0.02 \\
\hline \multicolumn{5}{|l|}{ Age category } \\
\hline $6-11$ years & 1.00 & - & 1.00 & - \\
\hline $12-16$ years & $0.22(0.14-0.36)$ & $<0.001$ & $0.21(0.12-0.35)$ & $<0.001$ \\
\hline \multicolumn{5}{|l|}{ Socio-economic status } \\
\hline Low & 1.00 & - & 1.00 & - \\
\hline Middle & $0.83(0.52-1.31)$ & 0.42 & $1.04(0.60-1.81)$ & 0.89 \\
\hline High & $1.57(0.87-2.85)$ & 0.13 & $1.21(0.58-2.53)$ & 0.61 \\
\hline Adverse childhood events & $1.02(0.90-1.15)$ & 0.75 & $0.96(0.83-1.10)$ & 0.55 \\
\hline Bully victimization & $0.97(0.91-1.03)$ & 0.29 & $0.98(0.91-1.04)$ & 0.47 \\
\hline Self-esteem & $1.06(1.00-1.13)$ & 0.06 & $1.09(1.01-1.17)$ & 0.03 \\
\hline Resilience & $0.98(0.96-1.01)$ & 0.18 & $1.00(0.97-1.03)$ & 0.80 \\
\hline Social support & $0.99(0.98-1.01)$ & 0.35 & $1.00(0.98-1.01)$ & 0.55 \\
\hline
\end{tabular}


adjusted model, higher self-esteem was associated with better oral hygiene, none of the psychosocial factors had significant association. The higher the self-esteem score, the higher the odds of having poor oral hygiene (AOR: 1.09; 95\% CI: 1.01-1.17; $p=0.03)$. In addition, sex and age were associated with poor oral hygiene in the adjusted models. Males had higher odds of having poor oral hygiene than did females (AOR: 1.78; 95\% CI: 1.10$2.88 ; p=0.02)$. Also, 12-16-year-old children had significantly higher odds of having poor oral hygiene than 6-11-year-old children in the adjusted model (AOR: 0.21 ; 95\% CI: 0.12-0.35; $p<0.001$ ).

Table 4 shows the factors associated with caries after the logistic regression analysis. In the unadjusted model, none of the psychosocial factors was significantly associated with caries. When the model was adjusted, two psychosocial factors became significantly associated with caries: self-esteem and perceived social support. The higher the self-esteem score, the lower was the odds of having caries (AOR: 0.91; 95\% CI: 0.85-0.98; $p=0.02$ ), and the higher the perceived social support, the lower the odds of having caries (AOR: 0.98; 95\% CI: 0.97-1.00; $p=0.02$ ).

Table 5 shows the factors associated with caries complications. None of the psychosocial factors was associated with caries complications in the unadjusted and unadjusted models. However, the socioeconomic status was significantly associated with caries complications in the adjusted model: The odds of having caries complication was lower for children with middle socio-economic status than for children with low socioeconomic status
(AOR: 0.02; 95\% CI: 0.00-0.06; $p=0.02$ ). No child with high socioeconomic status had caries complications.

\section{Discussion}

This is the first study conducted in Nigeria that queried if ACE and bully victimization are associated with oral diseases in children and adolescents, and how children and adolescents' psychological assets and resources are associated with oral diseases. The study findings indicate that though there was no association between presence of caries, caries complication, poor oral hygiene, ACE and bullying, there was an association between presence of caries, self-esteem and social support, and an association between poor oral hygiene and self-esteem. Resilience was not associated with the presence of caries, caries complication and poor oral hygiene. The study was conducted in a community with low caries prevalence confirming previous research [71] and thus, the results may be useful in helping to identify subpopulations with high caries risk who may benefit from strategies to reduce caries risk and ameliorate caries complication [72].

One of the strengths of this study is its large number of participants and the use of instruments that had been validated to measure the various constructs for the study population. In addition, the measure of ACE captures a wide range of possible events. Data was generated through a household survey making the findings representative of the study population. The study also contextualized the interplay between oral health and psychosocial profile in a population of children and

Table 4 Logistic regression analysis to determine psychosocial factors associated with dental caries in children 6-16-years-old resident in Ile-Ife, Nigeria $(N=1001)$

\begin{tabular}{|c|c|c|c|c|}
\hline Variables & $\begin{array}{l}\text { Odds ratio } \\
\text { (95\% Confidence interval) }\end{array}$ & $\boldsymbol{P}$ value & $\begin{array}{l}\text { Adjusted odds ratio } \\
\text { (95\% Confidence interval) }\end{array}$ & $P$ value \\
\hline \multicolumn{5}{|l|}{ Sex } \\
\hline Female & 1.00 & - & 1.00 & - \\
\hline Male & $0.95(0.56-1.62)$ & 0.86 & $0.89(0.52-1.52)$ & 0.66 \\
\hline \multicolumn{5}{|l|}{ Age category } \\
\hline $6-11$ years & 1.00 & - & 1.00 & - \\
\hline $12-16$ years & $1.95(0.82-4.6)$ & 0.13 & $1.94(0.81-4.67)$ & 0.14 \\
\hline \multicolumn{5}{|l|}{ Socioeconomic status } \\
\hline Low & 1.00 & - & 1.00 & - \\
\hline Middle & $1.41(0.81-2.45)$ & 0.23 & $1.53(0.78-3.01)$ & 0.21 \\
\hline High & $1.04(0.48-2.25)$ & 0.11 & $1.67(0.66-4.23)$ & 0.28 \\
\hline Adverse childhood events & $0.99(0.86-1.15)$ & 0.94 & $0.99(0.84-1.16)$ & 0.89 \\
\hline Bully victimization & $1.02(0.96-1.08)$ & 0.56 & $1.01(0.94-1.08)$ & 0.76 \\
\hline Self-esteem & $0.94(0.88-1.01)$ & 0.08 & $0.91(0.85-0.98)$ & 0.02 \\
\hline Resilience & $1.01(0.98-1.04)$ & 0.55 & $1.00(0.97-1.03)$ & 0.81 \\
\hline Social support & $0.99(0.98-1.00)$ & 0.12 & $0.98(0.97-1.00)$ & 0.02 \\
\hline
\end{tabular}


Table 5 Logistic regression analysis to determine psychosocial factors associated with caries complication in children 6-16-years-old resident in lle-lfe, Nigeria $(N=59)$

\begin{tabular}{|c|c|c|c|c|}
\hline Variables & $\begin{array}{l}\text { Odds ratio } \\
\text { (95\% confidence interval) }\end{array}$ & $\boldsymbol{P}$ value & $\begin{array}{l}\text { Adjusted odds ratio } \\
\text { (95\% Confidence interval) }\end{array}$ & $\boldsymbol{P}$ value \\
\hline \multicolumn{5}{|l|}{ Sex } \\
\hline Female & 1.00 & - & 1.00 & - \\
\hline Male & $2.82(0.47-16.76)$ & 0.26 & $1.62(0.08-32.02)$ & 0.75 \\
\hline \multicolumn{5}{|l|}{ Age category } \\
\hline $6-11$ years & 1.00 & - & 1.00 & - \\
\hline $12-16$ years & $0.16(0.02-1.18)$ & 0.07 & $0.06(0.00-1.56)$ & 0.09 \\
\hline \multicolumn{5}{|l|}{ Socioeconomic status } \\
\hline Low & 1.00 & - & 1.00 & - \\
\hline Middle & $0.47(0.09-2.59)$ & 0.39 & $0.02(0.00-0.60)$ & 0.02 \\
\hline Adverse childhood events & $0.78(0.40-1.49)$ & 0.45 & $0.34(0.08-1.39)$ & 0.13 \\
\hline Bully victimization & $0.69(0.41-1.15)$ & 0.16 & $0.73(0.44-1.22)$ & 0.23 \\
\hline Self-esteem & $1.01(0.75-1.35)$ & 0.95 & $1.47(0.80-2.71)$ & 0.22 \\
\hline Resilience & $0.91(0.81-1.02)$ & 0.10 & $0.99(0.84-1.18)$ & 0.94 \\
\hline Social support & $0.99(0.95-1.03)$ & 0.67 & $1.01(0.94-1.09)$ & 0.55 \\
\hline
\end{tabular}

adolescents using measures that have not been widely studied.

The study however, is cross-sectional and thus limited in its ability to determine the causality of the associations between psychosocial factors and oral health. The study population was recruited from one of the 774 local government areas of Nigeria thus making the study not representative of all of Nigeria. The sample is also not representative of all children and youths as the participants are in-school with context that differs from that of out-of-school children and adolescents. In addition, although the type of school [73] and body images and size [74] could result in bullying, we did not include this in the data analysis: data on type of school was not available in the primary data. Nonetheless, the study generated several hypotheses that can lead to further research on the inter-relationship between psychosocial factors, culture and oral health.

The study results indicate that the psychosocial factors interact in various ways with oral health problems in children. While the prevalence of caries was lower in children with lower self-esteem and those with higher social support, none of these factors were associated with caries complications. Lower self-esteem was also associated with higher prevalence of poor oral hygiene. All these associations, however, were weak with small effect sizes as indicated by the values of the odds ratios. This is new information on the possible effect of psychosocial factors on oral health though the pathways for the observed association is not clear. Children and adolescents with high perceived social support - in this case, emotional support [75-77] - may have positive outlook on life and may take less risk with their oral health by indulging less with alcohol consumption, tobacco smoking or use of psychoactive substances [78], which reduces the risk for caries [79]. The link between low self-esteem and low prevalence of caries is however, less clear and needs further studies. The association between low self-esteem and poor oral hygiene is plausible but the pathway in this study could not be deciphered -low self-esteem may have impacted negatively on oral hygiene practices, resulting in poor oral hygiene [80, 81], and/or conversely, poor oral hygiene may have resulted in the low self-esteem. Studies on self-esteem and prevalence of caries and poor oral hygiene are needed.

The prevalence of bully victimization was high when compared with reports from other countries. For example, the prevalence of adolescents reporting bully victimization ranged from $14.2-38.9 \%$ in Brazil [82-84], to $26 \%$ in 40 resource-rich countries [44], 32\% in United Kingdom [85], and 47\% in Jordan [86]. The prevalence of ACE was also high when compared with the prevalence in other countries - 25\% in Hungary [87], 46.3\% in the United States of America [88], and $46.4 \%$ in the United Kingdom [89]. It was however comparable to the prevalence of $68.2 \%$ in Germany [90].

Despite the high prevalence of ACE and bully victimization in this study, they were not significantly associated with caries, caries complications and poor oral hygiene, unlike the associations reported in previous studies [2, 20-23]. There may be several reasons for this. First, it may be too early to detect the impact of ACE and bully victimization on oral health. Adversities in childhood have a dose-response relationship with health problems [91]. In young children and adolescents, the mean number of bully victimization and adverse events 
is low. Also, adversities in childhood have impact on later-life development [92], so the study may be looking for the impact of ACE too early in the life-time trajectory of events as some define ACE as adverse events that occur in the first 18 years of life [93]. Its impact on the risk for caries and poor oral hygiene may therefore, be less detectable in persons younger than 18 years of age. However, previous studies have investigated and identified the impact of bully victimization on the risk for caries in adolescents younger than 18 years [24, 84]. Studying ACE and bully victimization before age 18 years allows for accurate recollection of events, reduce the risk of recall bias and thereby enables contemporaneous rather than retrospective data collection [94].

Second, stress from ACE and bully victimization may be attenuated by culture. While children who are exposed to stressors from ACE and bully victimization may develop internalizing (anxiety and depression) and externalizing (delinquency and violence against peers) symptoms [95-97], not all children develop these symptoms: these symptoms are moderated by resilience and access to social support [98]. It is also possible that access to social support changes the effects that ACE and bully victimization may have had on oral health. Also, the collectivism culture of the ethnic group of the study population - the Yorubas [99] - may moderate the perception of stress from ACE and bully victimization. Ngo and Le [98] reported that collectivism dampened the impact of some stressors by enabling individuals to marshal and rely on support and resources from others. Social support, which is usually highly available in collective societies, may ameliorate the impact of negative life events. However, when the individual's self-esteem is affected negatively by these life events, the negative impact of ACE and bully victimization on the risk of caries may be stronger.

Third, the relatively high prevalence of ACE and bully victimization observed in the study population might have imparted a norm status to them. If these phenomena are common, there is less variation among participants in the chances of experiencing them and consequently they cannot explain differences in oral health outcomes [100]. This complex inter-relationship between psychosocial factors and oral diseases needs further study.

\section{Conclusion}

The relationship between psychosocial factors and oral diseases is complex: While self-esteem and perceived social support had a protective effect on the risk of caries, they were not protective against poor oral hygiene. In all cases, the associations indicated weak effects. ACE and bully victimization were not associated with caries, caries complications, or poor oral hygiene. The possible effect of culture in moderating these relationships needs to be explored.

\section{Abbreviations}

ACE: Adverse childhood experiences; AOR: Adjusted odds ratio;

Cl: Confidence interval; dmft: Decay missing filled tooth; DMFT: Decay

Missing Filled tooth; IQR: Interquartile range; OR: Odds ratio

\section{Acknowledgements \\ We acknowledge the contributions of the study participants who took the time to respond to questions.}

\section{Authors' contributions}

MOF designed the study. OA collected the data. MOF, OO designed the data analysis plan. MOF developed the first draft of the manuscript. MOF, OO, OA and MET contributed to the development of the full manuscript and agreed to the final version of the manuscript and its submission for publication. All authors have read and approved the manuscript.

\section{Funding}

Not applicable.

\section{Availability of data and materials}

This is a secondary analysis of a primary data we accessed from the PI with the primary data. The data used for this study is presented in the

manuscript. The PI will the primary data is willing to make the data available on request.

Ethics approval and consent to participate

Ethics approval for the study was obtained from the Research and Ethics Committee of the Obafemi Awolowo University Teaching Hospitals Complex, Ile-Ife, Nigeria (ERC/2018/08/06). The study was conducted in line with the requirements of the Declaration of Helsinki. The primary study received written consent from the parents of all study participants; assent was obtained from children ages 12-16 years.

Consent for publication

Not applicable.

\section{Competing interests}

MOF is a Sectional Editor with the BMC Oral Health. MET is an Associate Editor with the BMC Oral Health. All other authors declare that they have no competing interests.

\section{Author details}

${ }^{1}$ Obafemi Awolowo University Teaching Hospitals Complex, Ile-lfe, Nigeria. ${ }^{2}$ Department of Child Dental Health, Obafemi Awolowo University, lle-lfe,

Nigeria. ${ }^{3}$ Faculty of Dentistry, Alexandria University, Qism Bab Sharqi, Egypt.

Received: 6 April 2020 Accepted: 8 June 2020

Published online: 11 July 2020

\section{References}

1. Zarse EM, Neff MR, Yoder R, Hulvershorn L, Chambers JE, Chambers RA. The adverse childhood experiences questionnaire: two decades of research on childhood trauma as a primary cause of adult mental illness, addiction, and medical diseases. Coll Med. 2019;6(1):1581447.

2. Bright MA, Alford SM, Hinojosa MS, Knapp C, Fernandez-Baca DE. Adverse childhood experiences and dental health in children and adolescents. Community Dent Oral Epidemiol. 2015:43:193-9.

3. Ford K, Brocklehurst P, Hughes K, Sharp CA, Bellis MA. Understanding the association between self-reported poor oral health and exposure to adverse childhood experiences: a retrospective study. BMC Oral Health. 2020;20(1): 51.

4. Crouch E, Radcliff E, Nelson J, Strompolis M, Martin A. The experience of adverse childhood experiences and dental care in childhood. Community Dent Oral Epidemiol. 2018:46(5):442-8.

5. Su S, Jimenez MP, Roberts CT, Loucks EB. The role of adverse childhood experiences in cardiovascular disease risk: a review with emphasis on plausible mechanisms. Curr Cardiol Rep. 2015;17(10):88.

6. Huffhines L, Noser A, Patton SR. The link between adverse childhood experiences and diabetes. Curr Diab Rep. 2016;16(6):54. 
7. Anda RF, Croft JB, Felitti VJ, Nordenberg D, Giles WH, Williamson DF, Giovino GA. Adverse childhood experiences and smoking during adolescence and adulthood. JAMA. 1999;282(17):1652-8.

8. Dental Health Services Victoria. Links between oral health and general health - the case for action. 2011. Accessible at: https://www.dhsv.org.au/_ data/assets/pdf_file/0013/2515/links-between-oral-health-and-generalhealth-the-case-for-action.pdf. Accessed: 21 Mar 2020.

9. Sabbah W, Folayan MO, El Tantawi M. The link between oral and general health. Int J Dent. 2019;2019:7862923.

10. Kabani F, Lykens K, Tak HJ. Exploring the relationship between adverse childhood experiences and oral health-related quality of life. J Public Health Dent. 2018;78(4):313-20.

11. Dorian B, Garfinkel PE. Stress, immunity and illness - a review. Psychol Med. 1987;17:393-407.

12. Warren KR, Postolache $\pi$, Groer ME, Pinjari O, Kelly DL, Reynolds MA. Role of chronic stress and depression in periodontal diseases. Periodontol. 2014; 64:127-38.

13. Hujoel PP, Hujoel MLA, Kotsakis GA. Personal oral hygiene and dental caries: a systematic review of randomised controlled trials. Gerodontology. 2018; 35(4):282-9.

14. Vasiliou A, Shankardass K, Nisenbaum R, Quiñonez C. Current stress and poor oral health. BMC Oral Health. 2016;16(1):88.

15. Shankardass K. Place-based stress and chronic disease: a systems view of environmental determinants. In: O'Campo P, Dunn JR, editors. Rethinking social epidemiology: towards a science of change. New York: Springer Publishing Company; 2012. p. 117-8.

16. Pearlin LI, Lieberman MA, Menaghan EG, Mullan JT. The stress process. J Health Soc Behav. 1981;22(4):337-56.

17. Sabbah W, Watt RG, Sheiham A, Tsakos G. Effects of allostatic load on the social gradient in ischaemic heart disease and periodontal disease: evidence from the third National Health and nutrition examination survey. J Epidemiol Community Health. 2008;62(5):415-20.

18. Buchwald S, Kocher T, Biffar R, Harb A, Holtfreter B, Meisel P. Tooth loss and periodontitis by socio-economic status and inflammation in a longitudinal population-based study. J Clin Periodontol. 2013;40(3):203-11.

19. Craig WM, Pepler DJ. Identifying and targeting risk for involvement in bullying and victimization. Can J Psychiatr. 2003;48:577-82.

20. All4health. Bullying: nothing to smile about. 2016. Available at: https://all4 oralhealth.wordpress.com/2016/02/11/bullying-nothing-to-smile/. Accessed 16 Mar 2020.

21. Cunningham SJ. The psychology of facial appearance. Dental Update. 1999; 26(10):438-43

22. Seehra J, Fleming PS, Newton T, DiBiase AT. Bullying in orthodontic patients and its relationship to malocclusion, self-esteem, and oral health-related quality of life. J Orthod. 2011;38(4):247-56.

23. Al-Bitar ZB, Al-Omari IK, Sonbol HN, Al-Ahmad HT, Cunningham SJ. Bullying among Jordanian school children, its effects on school performance, and the contribution of general physical and dentofacial features. Am J Orthod Dentofac Orthop. 2013;144(6):872-8.

24. Barasuol JC, Soares JP, Castro RG, Giacomin A, Gonçalves BM, Klein D, et al. Untreated dental caries is associated with reports of verbal bullying in children 8-10 years old. Caries Res. 2017;51(5):482-8.

25. King TL. Bad breath and school bullying. Dentistry for children. 2019 Available at: http://pediatricdentistorlando.com/bad-breath-school-bullying/. Accessed: 21 Mar 2020.

26. Phillips C, Beal KNE. Self-concept and the perception of facial appearance in children and adolescents seeking orthodontic treatment. Angle Orthod. 2009;79(1):12-6.

27. Fernandes MLDMF, Moura FMP, Gamaliel KS, Correa-Farria P. Dental caries and need of orthodontic treatment: impact on the quality of life of schoolchildren. Pesqui Bras Odontopediatr Clín Integr. 2013;13(1):37-43.

28. Low W, Tan S, Schwartz $\mathrm{S}$. The effect of severe caries on the quality of life in young children. Pediatr Dent. 1998;21(6):325-6.

29. Patel RR, Tootla R, Inglehart MR. Does oral health affect self perceptions, parental ratings and video-based assessments of children's smiles? Community Dent Oral Epidemiol. 2007;35(1):44-52.

30. Al-Omari IK, Al-Bitar ZB, Sonbol HN, Al-Ahmad HT, Cunningham SJ, Al-Omiri M. Impact of bullying due to dentofacial features on oral health-related quality of life. Am J Orthod Dentofac Orthop. 2014;146(6):734-9.

31. Gatto RCJ, Garbin AJI, Corrente JE, Garbin CAS. The relationship between oral health-related quality of life, the need for orthodontic treatment and bullying, among Brazilian teenagers. Dental Press J Orthod. 2019;24(2):7380.

32. da Silva AN, Alvares de Lima ST, Vettore MV. Protective psychosocial factors and dental caries in children and adolescents: a systematic review and meta-analysis. Int J Paediatr Dent. 2018; https://doi.org/10.1111/ipd.12375.

33. Antonovsky A. Health, stress and coping. London: Jossey-Bass; 1979.

34. Antonovsky A. Unraveling mystery of health. How people manage stress and stay well. San Francisco: Jossey-Bass; 1987.

35. Agou S, Locker D, Muirhead V, Tompson B, Streiner DL. Does psychological well-being influence oral-health-related quality of life reports in children receiving orthodontic treatment? Am J Orthod Dentofac Orthop. 2011;139: 369-77.

36. Turner SR, Rumsey N, Sandy JR. Psychological aspects of cleft lip and palate. Eur J Orthod. 1998;20:407-15.

37. Eriksson $M$, Lindstrom B. Bringing it all together: the salutogenic response to some of the most pertinent public health dilemmas. In: Morgan ADM, Ziglio E, editors. Health assets in a global context. New York: Springer; 2010. p. 339-52.

38. Herzog JI, Schmahl C. Adverse childhood experiences and the consequences on neurobiological, psychosocial, and somatic conditions across the lifespan. Front Psychiatry. 2018;9:420.

39. Poole JC, Dobson KS, Pusch D. Childhood adversity and adult depression: the protective role of psychological resilience. Child Abuse Negl. 2017;64: 89-100

40. Thoits PA. Social support as coping assistance. J Consult Clin Psychol. 1986; 54:416-23.

41. Locker D, Gibson B. The concept of positive health: a review and commentary on its application in oral health research. Community Dent Oral Epidemiol. 2006;34:161-73.

42. Morcillo C, Ramos-Olazagasti MA, Blanco C, Sala R, Canino G, Bird H, et al. Socio-cultural context and bulling others in childhood. J Child Fam Stud. 2015;24(8):2241-9.

43. Wolke D, Woods S, Stanford K, Schulz H. Bullying and victimization of primary school children in England and Germany: prevalence and school factors. Br J Psychol. 2001;92(Pt 4):673-96.

44. Craig W, Harel-Fisch Y, Fogel-Grinvald H, Dostaler S, Hetland J, SimonsMorton B, et al. A cross-national profile of bullying and victimization among adolescents in 40 countries. HBSC Violence \& Injuries Prevention Focus Group, HBSC Bullying Writing Group. Int J Public Health. 2009;54(Suppl 2): 216-24.

45. Sorrentino RM, Cohen D, Olson JM. Culture and social behavior (Ontario symposia on personality and social psychology series). Abingdon: Routledge; 2014.

46. Cherry K. Understanding collectivist cultures: how culture can influence behavior. 2020. Available at: https://www.verywellmind.com/what-arecollectivistic-cultures-2794962. Accessed: 20 Mar 2020.

47. Folayan MO, Haire B. Communitarian societies and public engagement in public health. Crit Public Health. 2017;27:6-13.

48. Fergus S, Zimmerman MA. Adolescent resilience: a framework for understanding healthy development in the face of risk. Annu Rev Public Health. 2005;26:399-419.

49. Chambers $C T$, Johnston C. Developmental differences in children's use of rating scales. J Pediatr Psychol. 2002;27(1):27-36.

50. Harter S, Whitesell NR. Developmental changes in children's understanding of single, multiple, and blended emotion concepts. In: Saarni C, Harris PL, editors. Children's understanding of emotion. Cambridge: Cambridge University Press; 1989. p. 81-116.

51. Metcalfe C. Biostatistics: a foundation for analysis in the health sciences. 7th edition. Wayne W. Daniel, Wiley. Stat Med. 2001;20(2):324-6.

52. Adekoya-Sofowora C, Nasir W, Oginni A, et al. Dental caries in 12-year-old suburban Nigerian school children. Afr Health Sci. 2006;6(3):145-50.

53. Olusanya O, Okpere O, Ezimokhai M. The importance of social class in voluntary fertility control in developing country. West Afr J Med. 1985;4:205-12.

54. Felitti VJ, Anda RF, Nordenberg D, Williamson DF, Spitz AM, Edwards V, et al. Relationship of childhood abuse and household dysfunction to many of the leading causes of death in adults. The Adverse Childhood Experiences (ACE) Study. Am J Prev Med. 1998;14(4):245-58.

55. Folayan MO, Oginni O, Arowolo O, El Tantawi M. Internal consistency and correlation of the adverse childhood experiences, bully victimization, selfesteem, resilience, and social support psychometric scales used with children and adolescents in sub-urban Nigeria. BMC Res Notes. (in Review). 
56. Espelage $\mathrm{DL}$, Holt M. Bullying and victimization during early adolescence: peer influences and psychosocial correlates. J Emot Abus. 2001;2:123-42.

57. Eze JE, Chukwuorji JC, Ettu PC, Zacchaeus EA, lorfa SK, Nwonyi SK. Bullying and suicide ideation: testing the buffering hypothesis of social support in sub-Saharan African sample. J Child Adolesc Trauma. 2019; https://doi.org/ 10.1007/s40653-019-00294-w.

58. Rosenberg M. Society and the adolescent self-image. Princeton: Princeton University Press; 1965.

59. Okoiye OE, Anyaochi NN, Onah AT. Moderating effect of cyberbullying on the psychological well-being of in-school adolescents in Benin Edo State Nigeria. Europ J Sustain Dev. 2015;4(1):109-18.

60. Aloba O, Olabisi O, Aloba T. The 10-item Connor-Davidson resilience scale: factorial structure, reliability, validity, and correlates among student nurses in Southwestern Nigeria. J Am Psychiatr Nurses Assoc. 2016;22(1):43-51.

61. Zimet GD, Dahlem NW, Zimet SG, Gordon K. The multidimensional scale of perceived social support. J Pers Assess. 1988;52:30-41.

62. Sarason IG, Sarason BR, Shearin EN, Pierce GR. A brief measure of social support: practical and theoretical implications. J Soc Pers Relat. 1987;4:497-510.

63. Agoha BCE, Ogwa F, Evbuoma K, Igbokwe DO, Idoko JO. Perceived social support, perceived stress as correlates of stress symptomatology among university students. Covenant Int J Pyschol. 2015;1(1):27-34.

64. Mohammad AH, Al Sadat N, Yim LS, Chinna K. Validity and reliability of the Hausa version of multidimensional scale of perceived social support index. Iran Red Crescent Med J. 2015;17(2):e18776.

65. Greene JC, Vermillion JR. The simplified oral hygiene index. J Am Dent Assoc. 1964;68:7-13.

66. WHO. World Health Organization oral health surveys. Geneva: Basic Methods; 1997.

67. Monse B, Heinrich-Weltzien R, Benzian H, Holmgren C, van Palenstein Helderman W. PUFA--an index of clinical consequences of untreated dental caries. Community Dent Oral Epidemiol. 2010;38(1):77-82

68. Umesi-Koleoso DC, Ayanbadejo PO, Oremosu OA. Dental caries trend among adolescents in Lagos, South-West Nigeria. West Afr J Med. 2007; 26(3):201-5.

69. Folayan MO, Sowole CA, Owotade FJ. Residential location and caries risk of preschool children in Lagos, Nigeria. Afr J Med Med Sci. 2012;41:43-8.

70. Nurius PS, Logan-Greene P, Green S. ACEs within a social disadvantage framework: distinguishing unique, cumulative, and moderated contributions to adult mental health. J Prev Interv Commun. 2012;40(4):278-90.

71. World Health Organisation. Ending childhood dental caries. WHO Implementation manual. 2019.

72. Zimmerman MA. Resiliency theory: a strengths-based approach to research and practice for adolescent health. Health Educ Behav. 2013;40(4):381-3.

73. Reisen A, Viana MC, Santos-Neto ETD. Bullying among adolescents: are the victims also perpetrators? Braz J Psychiatry. 2019;41(6):518-29.

74. Wang C, Li Y, Li K, Seo DC. Body weight and bullying victimization among US adolescents. Am J Health Behav. 2018;42(1):3-12.

75. Cohen S, Gottlieb BH, Underwood LG. Social relationships and health: challenges for measurement and intervention. Adv Mind Body Med. 2001; 17(2):129-41.

76. Cohen S, Mermelstein R, Kamarck T, Hoberman HM. Measuring the functional components of social support. In: Sarason IG, Sarason BR, editors. Social support: theory, research and applications. Dordrecht: Springer; 1985. p. 73-94.

77. Al-Rudainy O. Role of acculturation, social capital and oral health literacy on access to dental care among preschool children of Arabic-speaking immigrants in Toronto, Canada. Toronto: University of Toronto; 2011.

78. Cooke BD, Rossman MM, McCubbin HI, Pattersson JM. Examining the definition and assessment of social support: a resource for individuals and families. Fam Relat. 1988;37(2):211-6.

79. Greenberg JL, Lewis SE, Dodd DK. Overlapping addictions and self-esteem among college men and women. Addict Behav. 1999;24(4):565-71.

80. Huff M, Kinion E, Kendra MA, Klecan T. Self-esteem: a hidden concern in oral health. J Community Health Nurs. 2006;23(4):245-55.

81. Pazos CTC, Austregésilo SC, Goes PSA. Self-esteem and oral health behavior in adolescents. Cien Saude Colet. 2019;24(11):4083-92.

82. Azeredo CM, Levy RB, Araya R, Menezes PR. Individual and contextual factors associated with verbal bullying among Brazilian adolescents. BMC Pediatr. 2015;15:49

83. Moura DR, Nova Cruz AC, Quevedo LA. Prevalence and characteristics of school age bullying victims. J Pediatr. 2011;87:19-23.
84. Santos JA, Cabral-Xavier AF, Paiva SM, LeiteCavalcanti A. Prevalência e tipos de bullying em escolares Brasileiros de 13 a 17 anos. Rev Salud Publica (Bogota). 2014;16:173-83.

85. Agel M, Marcenes W, Stansfeld SA, Bernabé E. School bullying and traumatic dental injuries in East London adolescents. Br Dent J. 2014;26:217-21.

86. Al-Bitar ZB, Al-Omari IK, Sonbol HN, Al-Ahmad HT, Cunningham SJ. Bullying among Jordanian schoolchildren, its effects on school performance, and the contribution of general physical and dentofacial features. Am J Orthod Dentofac Orthop. 2013;144:872-88.

87. Ujhelyi Nagy A, Kuritár Szabó I, Hann E, Kósa K. Measuring the prevalence of adverse childhood experiences by survey research methods. Int J Environ Res Public Health. 2019;16(6):E1048.

88. Bethell CD, Davis MB, Gombojav N, Stumbo S, Powers K. Issue brief: a national and across state profile on adverse childhood experiences among children and possibilities to heal and thrive. Baltimore: Johns Hopkins Bloomberg School of Public Health; 2017. Available at: http://www.cahmi. org/projects/adverse-childhood-experiences-aces/. Accessed 28 Mar 2020.

89. Hughes K, Lowey H, Quigg Z, Bellis MA. Relationships between adverse childhood experiences and adult mental well-being: results from an English national household survey. BMC Public Health. 2016;16:222.

90. Häuser W, Schmutzer G, Brähler E, Glaesmer H. Maltreatment in childhood and adolescence: results from a survey of a representative sample of the German population. Dtsch Arztebl Int. 2011;108(17):287-94.

91. Chamberlain SR, Redden AS, Grant JE. Calorie intake and gambling: is fat and sugar consumption 'impulsive'? J Gambl Stud. 2017;33(3):783-93.

92. Adam EK, Chase-Lansdale PL. Home sweet home(s): parental separations, residential moves, and adjustment problems in low income adolescent girls. Dev Psychol. 2002;38:92-805.

93. Gilbert R, Widom CS, Browne K, Fergusson D, Webb E, Janson S. Burden and consequences of child maltreatment in high-income countries. Lancet. 2009;373:68-81.

94. Crouch E, Probst JC, Radcliff E, Bennett KJ, McKinney SH. Prevalence of adverse childhood experiences (ACEs) among US children. Child Abuse Negl. 2019;92:209-18.

95. Holmes CS, Yu Z, Frentz J. Chronic and discrete stress as predictors of children's adjustment. J Consult Clin Psychol. 1999;67:411-9.

96. West SG, Sandler I, Pillow DR, Baca L, Gersten JC. The use of structural equation modeling in generative research: toward the design of a preventive intervention for bereaved children. Am J Community Psychol. 1991;19:459-80

97. Youngstrom E, Weist MD, Albus KE. Exploring violence exposure, stress, protective factors and behavioral problems among inner-city youth. Am J Community Psychol. 2003:32:115-29.

98. Ngo HM, Le TN. Stressful life events, culture, and violence. J Immigr Minor Health. 2007:9(2):75-84.

99. Elegbe O, Nwachukwu I. A cross-cultural analysis of communication patterns between two cultures in Southwest Nigeria. Inkanyiso J Hum Soc Sci. 2017:9:52-65.

100. Burt BA, Ekland SA. Dentistry, dental practice, and the community. 6th ed. Philadelphia: Saunders; 2005

\section{Publisher's Note}

Springer Nature remains neutral with regard to jurisdictional claims in published maps and institutional affiliations.

Ready to submit your research? Choose BMC and benefit from

- fast, convenient online submission

- thorough peer review by experienced researchers in your field

- rapid publication on acceptance

- support for research data, including large and complex data types

- gold Open Access which fosters wider collaboration and increased citations

- maximum visibility for your research: over $100 \mathrm{M}$ website views per year

At $\mathrm{BMC}$, research is always in progress.

Learn more biomedcentral.com/submissions 